\title{
The Royal Society of New Zealand
}

$\mathrm{S}$ CIENTIFIC work in New Zealand, so far as research is concerned, has largely depended upon the organisation of the New Zealand Institute, which has now been honoured by the title of the Royal Society of New Zealand.

The New Zealand Institute Act was passed in 1867, and in March 1868 the body began to function. During the sixty-six years of its existence the Institute has encouraged workers in all branches of science and has published a large number of their researches. The first volume of its Transactions appeared in 1868, and annually (with one exception during the War) since that date the publication has been produced. It may truly be said that the whole set of sixty-four volumes contains an epitome of the research work in science that has been done in the Dominion.

The recognition of the value and importance of the scientific work of the members of the Institute by the grant of a Royal Charter is a matter that gives the greatest satisfaction to its members. It is perhaps only natural in such a country as New Zealand, where natural objects both animate and inanimate are in large part novel to people from Europe, that observational science would attract the greatest number of research workers. Actually it will be seen that articles on zoology, botany and geology have throughout filled a large proportion of its pages, now perhaps more than ever. Those whose work is in the sciences of chemistry and physics perhaps feel their remoteness from the centres of scientific life more acutely, and wish also to publish in journals which have a wider circulation than the Transactions of the New Zealand Institute could claim. Even so, it is a matter of great satisfaction to know that the first scientific research of Lord Rutherford appeared in its pages.

At the meeting of the Council of the Institute on
May 16, the actual change took place. The meeting received a letter from the Governor General, Lord Bledisloe, to whose initiative and great assistance the actual grant of the charter is largely due (see NATURE of July 14, p. 59). His Excellency's letter, which aroused great enthusiasm at the meeting, included the following significant words : "To starve knowledge (and especially that clearly ascertained and systematised knowledge which we designate science) or to stint it of its due reward is to court national disaster. If science, in the inevitable evolution of human genius, has contributed to economic adversity, it is because it has been applied in part only to the solution of human problems, and certain it is that only by the further application of science in all its ramifications and by a far more generous and enlightened recognition of its beneficent potentialities by the world's rulers will effective remedies for current human disorders be found."

In the evening, Prof. R. Speight, professor of geology in Canterbury College, Christchurch and president of the Royal Society of New Zealand, delivered an address in which he summarised the work of the Institute in various branches of scientific inquiry. $\mathrm{He}$ discussed the standing of the Institute (now the Royal Society) in the scientific life of the country in the past and at the present time. Prof. Speight stated that in his opinion "the activity of the Society and the interest it shows in scientific matters had never been greater".

The Council of the Royal Society were the guests of the president, Dr. J. Henderson, and Council of the Philosophical Society of Wellington on the following day. Addresses were delivered by Dr. Turner, Prof. Burbidge and Dr. L. Cockayne, and excursions were made to institutions and localities of scientific interest in the afternoon. The occasion provided much opportunity for seientific conference and discussion.

\section{Royal Photographic Society's Annual Exhibition}

$\mathrm{T}$ HE Royal Photographic Society's seventy-ninth annual exhibition was opened on September 7 and will remain open until October 6 . The hours are from 10 a.m. to 9 p.m. on all weekdays except Tuesdays and Fridays, when the closing hour will be 6 p.m. Admission is free.

As usual, the main part of the exhibition is pictorial, yet there is a considerable amount of work of scientific interest. Trade exhibits of apparatus and materials have been given greater prominence than in most former years. Particularly noticeable are the various substandard cinematograph cameras and projectors, some of which are now obtainable with soundrecording and reproducing equipment. The small hand camera, too, is to be seen in great variety with all its special accessory apparatus.

H. E. Edgerton and K.J. Germeshausen, of the Massachusetts Institute of Technology, show a series of instantaneous photographs of rapidly moving objects. The time taken for a single exposure in most of these is $1 / 75,000$ of a second; in one set of pictures, however, the exposure time was only $1 / 1,000,000$ of a second. The vortices in the air from an electric fan, a textile spindle turning 10,000 times in a minute, and several other rapidly moving objects are shown apparently stationary.
Aerial photography is fairly well represented, and there is one photograph by H. Frederick Low entitled "Archæology from the Air"; underlying ground conditions produce a variation in the appearance of a growing crop as seen from the air, which enables the outline of the original workings to be clearly mapped.

Mr. G. Aubourne Clarke, of Aberdeen, already well known for his studies of eloud formations, shows a fine series of photographs of clouds. For these he has been awarded the Hood Medal, which is given "in recognition of meritorious performance in any branch of photography".

In radiography, a very interesting development is shown by the Research Laboratories of the Eastman Kodak Company. Radiographs of small animals such as moths, beetles, etc. have been made by using exceptionally soft $\mathrm{X}$-rays. These rays, known as 'Grenz rays', will not penetrate the wall of a normal $\mathrm{X}$-ray tube, so that a special tube with a very thin window had to be constructed. Moreover, they record the texture of paper generally used for wrapping X-ray films, so the films had therefore to be enclosed in a special carrier, the front of which was made from a thin sheet of gelatine dyed to exclude visible and ultra-violet radiation. The tube itself 
was excited at relatively low potentials between 2 and 10 kilovolts.

Other work with soft X-rays produced by an ordinary tube is shown by $\mathbf{H}$. Flower and Messrs. Ilford Ltd. The structures of shells and flowers are thus illustrated.

From the very excellent Natural History Section mention may be made of an interesting series of photographs by H. Morrey Salmon illustrating the habits of the Manx shearwater. This bird comes to land only during the breeding season, when the colonies sometimes number thousands of pairs. On shore the birds move only by night. They nest in burrows which they share with rabbits. The nesting bird is said to remain underground during the hours of daylight, and is relieved by its mate at night. Some of the photographs were taken off Pembrokeshire at about 10.45 p.m. about midsummer at a distance of nearly two miles; others, taken by flashlight, were taken close to the birds.

An instructional exhibit by Messrs. Ilford Ltd. shows a 'working model' of the formation of halation circles on plates and films. Excellent examples of the influence of various backings in preventing halation are shown. Further exhibits by Ilford Ltd. in cooperation with Dr. Russell Reynolds show examples of cineradiographs of such subjects as the beating heart, moving joints, etc. The Cossor-Robertson cardiograph is demonstrated by Messrs. A. C. Cossor Ltd. and Ilford Ltd., together with typical cardiograms made on special photographic material manufactured by the latter firm.

\section{Magnetic Materials}

$\mathrm{F}$ OR some years past it has been the practice of line communication engineers to make use of iron-cored inductance coils and transformers at speech frequencies and even at carrier frequencies up to 50,000 cycles per second. The cores of such coils were usually composed of iron or a magnetic alloy in the form of wire or of powder embedded in a suitable binding material. During the past year or so, the attention of those responsible for the design and production of wireless receivers has been directed to the possibility of using such magnetic cores in coils and transformers, the frequencies of operation of which may exceed one million cycles per second. It has been claimed that broadcasting receivers giving better performance in a smaller space can be designed by the use of such coils, on account of the facility in screening and the more effective coupling between the circuits which these coils afford.

A report*, recently published by the Radio Research Board, summarises existing knowledge, both theoretical and experimental, of the behaviour of magnetic materials at radio frequencies with the object of assisting those engaged in the application of these materials in the manner outlined above. The subject is surveyed in an approximately analytical manner intended to illustrate the individual proper. ties, such as permeability, hysteresis and dielectric loss of the various materials examined; and, where the quantitative data permit, typical numerical values are assigned to these properties for various

* Department of Scientific and Industrial Research. Radio Research. Special Report No. 14. "Magnetic Materials at Radio Frequencies, A Critical Survey of Present Knowledge." By F. M. Colebrook, (London: H.M. Stationery Office, 1934.) 6d. net.

\section{at Radio Frequencies}

frequencies up to about 2,000 kilocycles per second. It appears that these electrical properties of ferro. magnetic core materials may be expressed in terms of permeability and power-factor in a manner analogous to the use of permittivity and power. factor for dielectrics.

From the information summarised in this report, it is concluded that the effective permeability of magnetic powder compositions is necessarily low compared with that of the magnetic material, and that it depends mainly upon the size of the particles employed and the spacing between them, rather than upon the permeability of the magnetic constituent. It is probable, though not certain, that the greater part of the total radio frequency losses in composite magnetic materials is due to eddy-current formation and a consequent skin-effect in flux distribution. There are at present available a number of iron powder compositions in which, by sufficiently fine division of the magnetic material and provision of adequate particle insulation, the total losses are reduced to a value which gives an economic permeability of from 4 to 10 up to frequencies of about 2,000 kilocycles per second. It is not known to what extent the behaviour of such material is consistent with theory, nor is there any certain knowledge of the constitution of the losses. Further, it is concluded that there is no evidence indicating that the limit of improvement in such materials has yet been reached.

The useful lines of future investigation of the subject are clearly indicated in the report, which undoubtedly forms a clear and concise introduction to this field of research in radio frequency technique.

\section{Determination of the Molecular Weights of Colloids}

$I^{\mathrm{N}}$ the January issue of the Berichte der deutschen chemischen Gesellschaft Prof. H. Staudinger discusses the validity of the method of deducing the molecular weight of a colloid of high molecular complexity from observations of its specific viscosity. The author claims that this new method is applicable to the investigation of numerous complex naturally occur. ring substances such as cellulose and india-rubber, since many physical properties such as elasticity, ductility, solubility, etc., are functions of the length of the molecular chain. Older methods of determining molecular weights of complex molecules are more restricted in their application. Thus the cryoscopic methods give very low results in dilute solutions and in more concentrated solutions the relation between molecular weight and osmotic pressure is no longer simple. The diffusion method is only suitable for particles of spherical shape and can therefore not be applied to the long fibre-molecules of many natural colloids.

An earlier account of Prof. Staudinger's views is to be found in the Transactions of the Faraday Society of January 1933, and the main object of this recent paper is to examine certain experimental evidence 